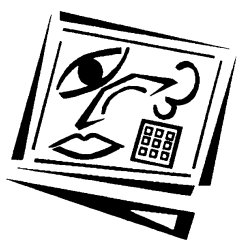

\title{
A kind of expertise reversal effect: Personalisation effect can depend on domain-specific prior knowledge
}

\author{
Klaus D. Stiller and Rosemarie Jedlicka \\ University of Regensburg
}

\begin{abstract}
In instructional multimedia design, it is often recommended that text accompanying pictures be presented in a personalised style to promote learning. The superiority of personalised over formal text may be explained using social agency theory (Mayer, $2005 b$ ), but it has not been investigated empirically whether such effects are valid in classroom settings, or depend on learner characteristics such as domain-specific prior knowledge. In this research, 65 pupils from the 10th grade of German grammar schools received computerised instructions about the structure of the human eye, containing static pictures and on screen text. The texts were written either in formal or in personalised style. Personalisation of the formal text was reached by replacing 130 impersonal articles with second person possessive pronouns and 24 third person articles with second person constructions. For learners with low prior knowledge, personalisation improved drawing and labeling performance, as well as the verbalisation of structural knowledge and transfer. For learners with higher prior knowledge, only labeling and drawing performance were improved, whilst structural knowledge was not affected and transfer performance was reduced.
\end{abstract}

\section{Introduction}

We can enhance learning from texts and pictures, i.e. multimedia learning, by optimising the cognitive or motivational conditions of the learning situation (Mayer, Fennell, Farmer \& Campbell, 2004). In cognitive aspects, well and badly designed multimedia instructions differ in the way they impose load on working memory. According to the cognitive load theory (Sweller, 1999), learning occurs when the overall cognitive load does not overburden working memory capacity and when as much capacity as available can be dedicated to schema acquisition and automation. Cognitive overload is mostly created by extraneous and intrinsic load. Extraneous load arises from the presentation manner of the material and is thought to be detrimental to learning because it has nothing to do with the construction or automation of schemas. Intrinsic load depends on the complexity of the learning task and the difficulty of the learning material and is the basic amount of processing required for understanding a presentation. Minimising extraneous load means designing the information presentation in an optimal fashion. Minimising intrinsic load means controlling information complexity by means of didactics. By minimising these loads, learners are more likely to engage in schema acquisition and automation that impose germane load. Maximising germane load means fostering schema acquisition. In motivational aspects, means of fostering learning are intended to increase germane load. In this aspect, one way to affect motivation was found in the personalisation of texts. 
In the following, the personalisation principle and its empirical base are introduced, followed by two theoretical explanations of personalisation effects. Then a research gap is revealed, i.e. the dependence of personalisation effects on domain-specific prior knowledge, and the experimental hypotheses are derived.

\section{The personalisation principle and its empirical evidence}

The personalisation principle of multimedia design recommends presenting texts in conversational rather than formal style in conjunction with dynamic or static pictures, because learners learn more effectively with personalised texts (Mayer, 2005b). The superiority of personalised over formal texts was demonstrated in multiple studies and mainly observed in measures of retention and transfer (Moreno \& Mayer, 2000, 2004; Mayer et al., 2004). Table 1 provides an overview about experiments on personalisation effect, also showing the effect sizes $d$ and the statistical significance of group comparisons.

Table 1: Overview about personalisation effects on retention and transfer performance

\begin{tabular}{|c|c|c|c|c|c|}
\hline \multirow{2}{*}{ Media context } & \multirow{2}{*}{ Content } & \multirow{2}{*}{\multicolumn{2}{|c|}{ Based on ... }} & \multicolumn{2}{|c|}{ Effect sizes $d$} \\
\hline & & & & Retention & Transfer \\
\hline \multirow[t]{2}{*}{ Narration and animation } & Lightning & $\begin{array}{l}\text { Moreno \& Mayer } \\
(2000)\end{array}$ & Exp. 1 & .15 & $1.04^{*}$ \\
\hline & Respiration & $\begin{array}{l}\text { Mayer et al. } \\
(2004)\end{array}$ & $\begin{array}{l}\text { Exp. } 1 \\
\text { Exp. } 2 \\
\text { Exp. } 3\end{array}$ & $\begin{array}{l}.00 \\
-.23 \\
.39\end{array}$ & $\begin{array}{l}.52^{*} \\
.99^{*} \\
.79^{*}\end{array}$ \\
\hline Visual text and animation & Lightning & $\begin{array}{l}\text { Moreno \& Mayer } \\
(2000)\end{array}$ & Exp. 2 & .20 & $1.61^{*}$ \\
\hline $\begin{array}{l}\text { Interactive, agent-based } \\
\text { multimedia game using } \\
\text { visual text }\end{array}$ & Botany & $\begin{array}{l}\text { Moreno \& Mayer } \\
\text { (2000) }\end{array}$ & Exp. 4 & $.63^{*}$ & $1.48^{*}$ \\
\hline \multirow{2}{*}{$\begin{array}{l}\text { Interactive, agent-based } \\
\text { multimedia game using } \\
\text { narration (desktop comp- } \\
\text { uter and virtual reality) }\end{array}$} & \multirow[t]{2}{*}{ Botany } & $\begin{array}{l}\text { Moreno \& Mayer } \\
(2000)\end{array}$ & $\begin{array}{l}\text { Exp. } 3 \\
\text { Exp. } 5\end{array}$ & $\begin{array}{l}1.05^{*} \\
.62^{*}\end{array}$ & $\begin{array}{l}1.84^{*} \\
1.08^{*}\end{array}$ \\
\hline & & $\begin{array}{l}\text { Moreno \& Mayer } \\
(2004)\end{array}$ & & $.92^{*}$ & $1.75^{*}$ \\
\hline
\end{tabular}

Notes for Table 1

a. Personalisation effects on retention and transfer performance were measured by tests requiring learners to remember the presented information and to use the presented information to solve new problems (Mayer, 2005b), respectively.

b. Effect sizes $d$ were computed as the difference between the means of the personalised and the non-personalised groups divided by the pooled standard deviations (Cortina \& Nouri, 2000; * statistically significant effect).

c. Effect sizes $d$ of range .20 to .50 are interpreted as small, of range .50 to .80 as medium, and of $>.80$ as large (Cohen, 1988). Hence, effect sizes $d$ of .00 reflect no differences and no effect; effect sizes of 1.00 reflect a large effect, meaning that the average score of the personalised group is a standard deviation greater than the average score of the non-personalised group.

Two major techniques for creating personalised texts are (1) to use you and $I$ and the associated possessive pronouns, rather than solely relying on third-person constructions, and (2) to add sentences in which the instructor makes direct comments to the learner (Mayer, 2005b). Table 2 gives an overview about the means of personalisation used in the experiments. 
Table 2: Overview about the means of personalisation used in the experiments

\begin{tabular}{|c|c|c|c|}
\hline Media context & Content & Based on ... & Means of personalisation \\
\hline $\begin{array}{l}\text { Narration accompany- } \\
\text { ing an animation }\end{array}$ & Lightning & $\begin{array}{l}\text { Moreno \& Mayer } \\
(2000): \text { Exp. } 1\end{array}$ & \multirow{2}{*}{$\begin{array}{l}\text { Using first and second person } \\
\text { constructions and direct comments to } \\
\text { the learner }\end{array}$} \\
\hline $\begin{array}{l}\text { On screen text accom- } \\
\text { panying an animation }\end{array}$ & Lightning & $\begin{array}{l}\text { Moreno \& Mayer } \\
\text { (2000): Exp. } 2\end{array}$ & \\
\hline $\begin{array}{l}\text { Narration } \\
\text { accompanying an } \\
\text { animation }\end{array}$ & Respiration & $\begin{array}{l}\text { Mayer et. al. (2004) } \\
\text { Exps. 1, 2, and } 3\end{array}$ & $\begin{array}{l}\text { Replacing twelve instances of the } \\
\text { article the by your in a } 100 \text { word } \\
\text { narration }\end{array}$ \\
\hline $\begin{array}{l}\text { Interactive, agent-based } \\
\text { multimedia game using } \\
\text { narration }\end{array}$ & Botany & $\begin{array}{l}\text { Moreno \& Mayer } \\
\text { (2000): Exp. } 3\end{array}$ & \multirow{2}{*}{$\begin{array}{l}\text { Using first and second person } \\
\text { constructions, adding questions and } \\
\text { direct comments to the learner; } \\
\text { transforming formal to informal style } \\
\text { (including some greater grammatical } \\
\text { changes) }\end{array}$} \\
\hline $\begin{array}{l}\text { Interactive, agent-based } \\
\text { multimedia game using } \\
\text { on screen text }\end{array}$ & Botany & $\begin{array}{l}\text { Moreno \& Mayer } \\
\text { (2000): Exp. } 4\end{array}$ & \\
\hline $\begin{array}{l}\text { Interactive, agent-based } \\
\text { multimedia game using } \\
\text { narration }\end{array}$ & Botany & $\begin{array}{l}\text { Moreno \& Mayer } \\
\text { (2000): Exp. } 5\end{array}$ & $\begin{array}{l}\text { Using first and second person } \\
\text { constructions (including some greater } \\
\text { grammatical changes) }\end{array}$ \\
\hline $\begin{array}{l}\text { Interactive, agent-based } \\
\text { multimedia game using } \\
\text { narration }\end{array}$ & Botany & $\begin{array}{l}\text { Moreno \& Mayer } \\
(2004)\end{array}$ & $\begin{array}{l}\text { Using first and second person constr- } \\
\text { uctions, adding questions and direct } \\
\text { comments to the learner; transforming } \\
\text { formal to informal style (including } \\
\text { some greater grammatical changes) }\end{array}$ \\
\hline
\end{tabular}

Mayer et al. (2004; Exps. 1 to 3) used a 60 second narrated animation about the human respiratory system. They only minimally changed the text used, by replacing twelve instances of the article the by your in a 100 word narration. This was the smoothest text modification of formal to personalised style appearing in literature. No pre-selection of probands in respect of prior knowledge was made. Introducing greater changes in personalisation, Moreno and Mayer (2000; Exps. 1 and 2) used a 140-second animation with either narration or on screen text about lightning formation. The personalisation of the text was reached by using first and second person constructions and adding direct comments to the learner. Only learners with low prior knowledge on meteorology were recruited. All five experiments revealed the superiority of personalised over formal texts in respect of transfer performance, but retention was not affected.

The most invasive changes in order to create a personalised style out of formal texts were done by Moreno and Mayer (2000, Exps. 3 to 5; 2004). They used an environmental science simulation game in which the learners interacted with an on screen agent named Herman-the-Bug either presented on a desktop computer (Moreno \& Mayer, 2000, 2004) or by using a head-mounted display (Moreno \& Mayer, 2004). Personalisation was mainly reached by using first and second person constructions and inserting questions (only Exp. 5 didn't use questions) to the learner. In exception to Moreno and Mayer (2000; Exps. 1 and 2) and Mayer et al. (2004), the sentences were also frequently accompanied by a variation in the grammatical structure. Moreno and Mayer (2004) used instructions lasting between 14 and 16 minutes and low prior knowledge learners. Moreno and Mayer (2000) used instructions lasting between 24 and 28 minutes, but no observations about learners' prior knowledge were given. All of the four experiments revealed the superiority of personalised over formal texts in respect of retention and transfer performance. 


\section{Explaining personalisation effects}

It was argued that personalised texts inspire learners to engage in deeper meaningful processing of information, resulting in a more coherent and complete mental model of the subject, which finally results in a better learning outcome (Mayer et al., 2004). There are mainly two competing ways - a motivational and a cognitive one - to explain how this deeper processing is reached. The motivational view stresses social aspects and the cognitive view the aspect of self-referencing. Both aspects are not mutually exclusive.

In a motivational view, personalisation is seen as an instance of using social cues in multimedia instructions (Mayer, 2005b). In order to explain effects of social cues, the social agency theory was introduced (Mayer, 2005b; see Figure 1). Against this background, it is assumed that social cues may prime the activation of social responses in learners, "such as the commitment to try to make sense out of what the speaker is saying" (Mayer, 2005b, p. 202). Especially, Reeves and Nass (1996) provided evidence against a communicational background that people have a natural predisposition to apply the same dynamics from human-human to human-computer interactions. A social response should lead to a higher motivation - mostly called interest (e.g. Mayer et al., 2004) - to engage in active cognitive processing and subsequently to deeper processing during learning, which was also evidenced by research on interest (Hidi \& Baird, 1988; Renninger, Hidi \& Krapp, 1992; Wade, 1992). Consequently, this improvement of learning should be reflected in a better test performance (Hidi \& Baird, 1988; Mayer, 2001; Renninger, Hidi \& Krapp, 1992; Wade, 1992).

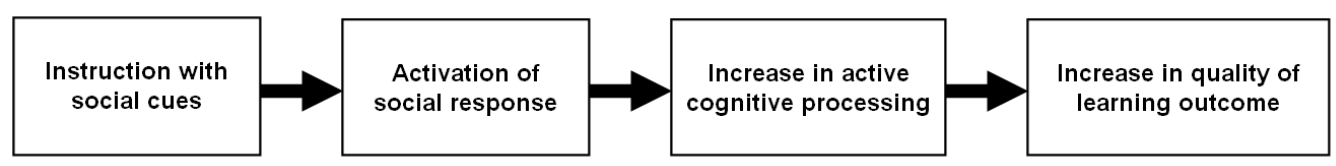

Figure 1: How social cues should work according to the social agency theory (Mayer, 2005b, p. 203).

Some evidence for the social cues explanation was found by Moreno and Mayer (2004), who tried to measure if learners feel a social relation with a virtual instructor (Reeves \& Nass, 1996). Indeed, they found evidence with learners' ratings of their physical presence (being in and interacting in a place) and the instructor's social presence (friendliness and helpfulness of the program) as well as some other indicators, which were theoretically assumed to be consecutively influenced by social cues like difficulty ratings of the instruction. On the other hand, there are also studies that did not support the social cues assumption (Mayer et al., 2004; Moreno \& Mayer, 2000), but they were criticised for using inadequate measures of social response like program ratings reflecting a joint measure of interest, motivation, and understanding as well as the program's perceived difficulty and friendliness, or measures of interest like counting smiles while learning.

From a cognitive view, the personalisation effect is considered to be related to the selfreference effect (Moreno \& Mayer, 2000). The self-reference effect reflects the aspect that people remembered information better, when it was encoded with respect to themselves rather than with respect to other referential frames (Symons \& Johnson, 1997). Turco (1996, p. 1047) thinks that information only needs to be "somehow related 
to the self" in order to be more easily remembered. Research has shown that selfreference promotes elaboration and organisation of information (Rogers, Kuiper \& Kirker, 1977; Symons \& Johnson, 1997). Thereby, it was also practised to vary selfreference by varying the communicational style of the experimental instructions. High self-referencing was realised by addressing probands directly and encouraging them to refer information to themselves, e.g. to their thoughts and feelings (Truco, 1996). The material to be learned was not manipulated in a self-referencing way. From this point of view, personalised instructional explanations are considered to enhance learning because personalisation is a way to force referencing information to the self, thus enhancing elaboration and organisation of information and leading to a better learning outcome. Especially, learners are more disposed to activate their relevant prior knowledge and to relate new information to it, hence to process the material more deeply (Moreno \& Mayer, 2000). So it might not be a social response and an associated increase in the learner's motivation that mediates processing, but rather the learner's feeling that the learning material is personally relevant. It was also theorised and empirically shown that this kind of relevance increases motivation (e.g. Keller \& Suzuki, 1988).

The motivational view is preferred and dominates the field of explaining personalisation effects, although evidence for a social explanation of personalisation effects is relatively scarce and not convincing in general. The cognitive view was mostly neglected and hence also not empirically proven. Therefore, in respect of the social agency theory, the core aspect is to show that social processes are involved to produce personalisation effects, because a self-referencing view also predicts an increase of interest, active cognitive processing, and learning outcome.

\section{Research gap}

In a variety of studies and instructional designs, it was found that design principles depend on domain-specific prior knowledge (Kalyuga, 2007), but how the personalisation principle might depend on it has not been investigated yet. This is the central research gap, which is addressed in this study. Kalyuga (2007) gave recently an overview about studies, revealing interaction effects of domain-specific prior knowledge with well founded instructional design principles. In general, it was shown that what is effective for low prior knowledge learners might be ineffective or even disturbing for learners with high prior knowledge, i.e. what is known as the expertise reversal effect (Kalyuga, 2007). Higher prior knowledge in a specific domain can be regarded as being a protection factor against badly designed information presentations, but also can handicap information processing in the way that for high knowledge learners even the badly designed instruction could be better. One way to explain the latter effect is as follows. With experienced learners, guidance of information processing by instruction presentation collides with guidance by schema of long-term memory. Two active guidances are cross-related and integrated concerning their overlapping components; thus producing unnecessary load, because it is difficult to ignore the instructional guidance. Low experienced learners do not possess any schemas of their own that help them to deal with new information. For low experienced learners, well-designed instructions guide information processing and serve as a substitute for schemas (Kalyuga, 2007).

Further on, some other aspects are addressed. The following experiment was conducted with pupils within a classroom setting at school using a learner-sequenced 
and learner-paced computerised instruction with static pictures, which is a more realistic, economically valid environment, while still maintaining rigorous experimental control. Until now, studies involved college students in laboratory settings, either using short narrated animations or longer lasting simulation games, which were often based on a set of animations. This experiment also includes a picture labelling and drawing task as well as a verbal structure and transfer task in order to identify the level of effects more precisely. Formerly, only measures of retention and problem solving transfer were used.

\section{Research questions and hypotheses}

We tested whether a personalised text was superior to a formal text by asking pupils to rate their elaborative processing (= active cognitive processing; see Figure 1 ) as well as to work on a verbal structure task, a drawing task, a labelling task and a transfer task after studying an instruction with static pictures and on screen text. Although the personalisation principle was found using the English language, it is also expected to be valid for German or other languages, in which formalised and personalised text styles are possible. Additionally, effects were analysed with respect of domain-specific prior knowledge.

Analogously to the personalisation effect, learners who work with personalised instructions should gain more knowledge and judge their active processing as higher than learners studying with non-personalised texts. According to the social agency theory, personalised text should prime the activation of social responses in learners, which should lead to a higher motivation to engage in active cognitive processing and subsequently to deeper processing during learning and hence in a better test performance. The perspective of self-reference also predicts that personalised texts promote elaboration and organisation of information by fostering the integration of new information to the self as well as a better test performance. Especially, personalisation effects should be evidenced for learners with low prior knowledge, because these learners were used in all former studies.

On the other hand, we assume that social cues are more important for less experienced learners than for more experienced learners. Therefore, personalisation effects should decrease or even vanish for higher prior knowledge learners when social cues are assumed to be less effective with growing prior knowledge. For example, one might assume that a higher level of prior knowledge concurrently indicates a higher level of interest in the subject to be learned and that therefore a smaller or even no increase of the motivational level is affected by introducing social cues. Analogously to the expertise reversal effect, self-referencing could mean a help for low experienced learners' processing of new information, but a disturbance of schema guided processing for high experienced learners.

\section{Method}

\section{Participants}

Sixty-five pupils of two German grammar schools from the 10th grade participated in the experiment. The average age was 16.08 years $(\mathrm{SD}=.48$, range 15 to 18 years) and the mode $16(n=53)$. Thirty-two pupils served in the personalised-text group, and 33 
served in the formal-text group. Fourty-eight pupils were female ( 23 and 25 pupils in the personalised-text and the formal-text group, respectively) and 17 male (nine and eight pupils in the personalised-text and the formal-text group, respectively). Experimental groups were checked for comparability concerning age and sex and were found to be indifferent. The Chi-square test was insignificant in respect of sex distribution on groups (Chi-squared $=.13, \mathrm{df}=1, \mathrm{~ns}$ ) as was the Welch test in respect of the groups' age averages $\left(\mathrm{M}_{\mathrm{formal}}=16.06, \mathrm{SD}=.35, \mathrm{M}_{\text {personalised }}=16.09, \mathrm{SD}=.59\right.$, Welch-t $(50.06)=.28, \mathrm{~ns})$.

\section{Computerised instructions}

The learning content was about the human eye and presented by text and pictures. For the instructional presentation, a schematic picture of a horizontal section through the eye and a frontal view on the eye were used (see Figure 2). Access to text was performed by clicking on parts of the pictures. Learners had to explore the pictures and find out which parts of the pictures were clickable and led to texts. Therefore, if the cursor of the mouse was moved over a link, the part of the picture changed its colour to green. After clicking on a link, that part of the picture stayed green until a new text unit was requested. In the cross-section of the eye, the following parts functioned as links: cornea, pupil, iris, lens, ciliary muscles, vitreous body, sclera, choroid, retina, optic disc, fovea, and optic nerve. As a 13th link, the surrounding of the eye was used; it led to a short description of the visual stimulus' way through the eye. In the frontal picture, only three links were placed which were combined with the analogous link in the other picture: sclera, pupil, and iris. If the cursor was placed over one of the links of one picture, the link of the other picture was also cued.

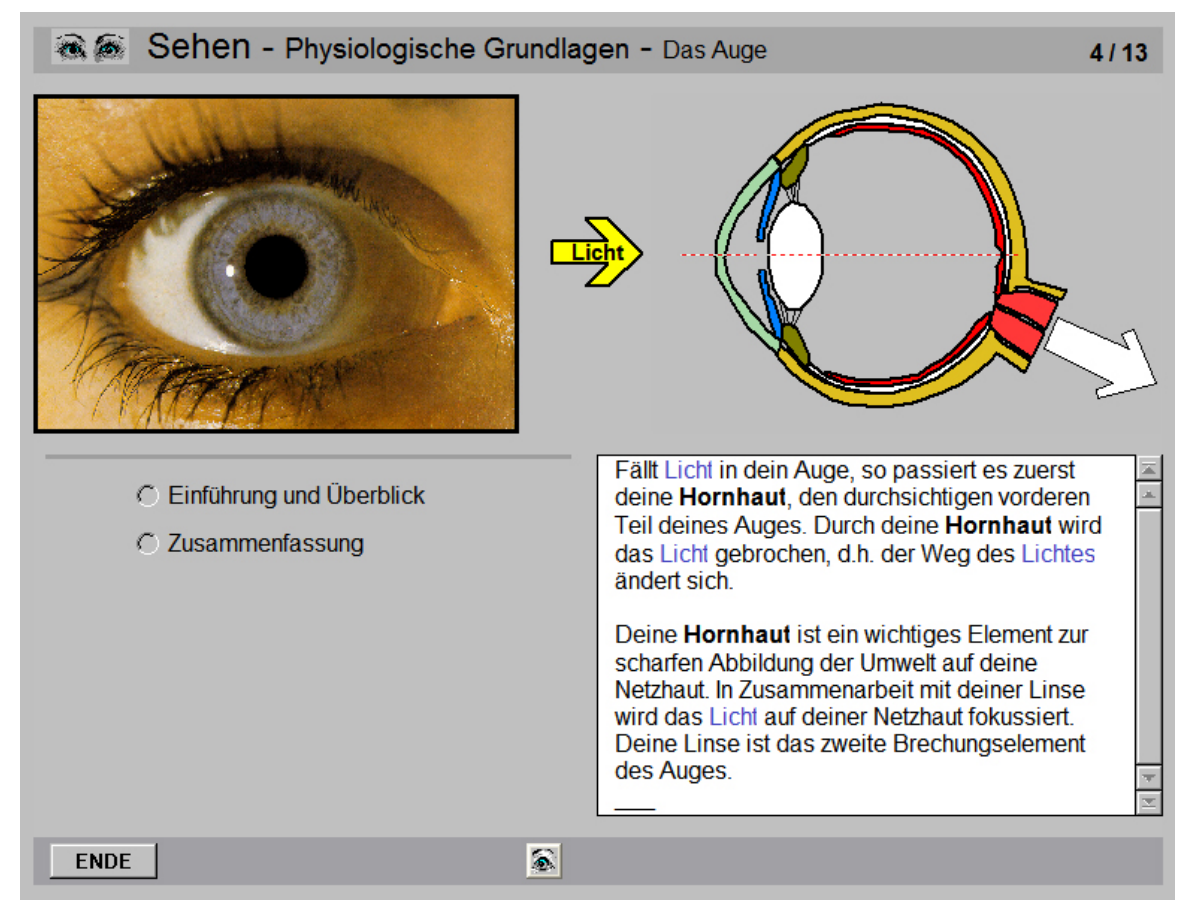

Figure 2: Screenshot of the program with personalised text. 
Only texts differed between both treatment groups. The text of the non-personalised, formal instruction contained 1116 words. The text was personalised by replacing 130 indefinite articles with possessive pronouns (e.g. "runs to the brain" to "runs to your brain") and by replacing 24 third person with second person constructions (e.g. "one sees" to "you see"). In German language, these replacements are sometimes accompanied with an increase of words due to grammatical changes (e.g. "zieht weiter zum Gehirn" was changed to "zieht weiter zu deinem Gehirn"). Thus, the personalised version consisted of 1136 words. The texts described the elements of the eye, their features and functions.

A couple of numbers placed in the top right corner of the screen showed how many links had already been used and how many links existed at all. In order to guarantee that no links were missed, the learners could trigger a highlighting process by pushing a button, whereby the unused links were successively cued for 2 seconds each. On the left side of the text field two radio buttons were placed for requesting an introduction and a summary of the section.

42 terms in the texts served as links to the glossary. After clicking on these words marked in blue, a window opened and an explanation was shown. The text units of the glossary included such links as well. The terms are part of a basic knowledge of physiology.

\section{Procedure}

Participants were tested in five groups consisting of 10 to 19 pupils, who were assigned randomly to either the personalised or the formal instruction. In practice, a pupil receiving a formal text was placed alongside a pupil using personalised text. At the beginning, the participants were introduced to the experiment for roughly 5 minutes. Then they were asked about their demographics (e.g. age and gender) and finally completed a test of prior knowledge. Participants completed the questionnaire at their own pace, but they had to wait for the slowest to finish before going on to the next stage of the experiment. After this pre-testing phase, the pupils were introduced to the handling of the instructional program for about 5 minutes. Following this, the subjects learned for exactly 13 minutes with their treatment instruction. Before learning, the experimenters announced the task: "Work through the whole program and learn the contents. Afterwards you have to take a test". It was clear that the pupils should study fully the information units about the eye and that the glossary units were options that could be studied when wanted. Pre-testing of the program guaranteed that the contents could be worked through by most pupils in about 10 minutes. After the learning phase, they rated their use of elaborative learning strategies and took a performance test. The whole experiment took about 60 minutes.

\section{Means of measurement}

Prior knowledge, active cognitive processing as well as four kinds of performance were assessed. Table 3 lists each of the questions constituting the measurement scales.

Prior knowledge was measured by eight multiple choice questions. Four answers were offered for each question along with an option to mark "I do not know". One of the answers was correct. Each answer was scored with a maximum of one point. 
Table 3: Questions constituting the measurement scales

\begin{tabular}{|c|c|}
\hline Scales & Questions \\
\hline Prior & $\begin{array}{ll}1 & \text { What is regulated by the ciliary muscles? }\end{array}$ \\
\hline \multirow[t]{7}{*}{ knowledge } & 2 What happens in the optic chiasm? \\
\hline & 3 What is the function of the choroids? \\
\hline & 4 What kinds of photo receptors exist? \\
\hline & $\begin{array}{l}5 \text { What is the area of the retina called on which the projection of an object falls } \\
\text { when it is fixated? }\end{array}$ \\
\hline & 6 What is the area of the brain called, which is mainly responsible for vision? \\
\hline & 7 What is the blind spot of an eye? \\
\hline & 8 What cells of the retina build up the optic nerve? \\
\hline \multirow{6}{*}{$\begin{array}{l}\text { Elaborative } \\
\text { learning } \\
\text { strategies }\end{array}$} & \begin{tabular}{|l|l}
1 & I thought about the meaning or intention of the content.
\end{tabular} \\
\hline & 2 I've tried to recapitulate what I read in my own words. \\
\hline & 3 While reading, some of my own personal experiences crossed my mind. \\
\hline & 4 While learning, I had pictographic conceptions of the content in my mind. \\
\hline & 5 While learning, I've made my own thoughts concerning the content. \\
\hline & 6 Imaginary I related some issues of the content to my own body. \\
\hline \multirow{5}{*}{$\begin{array}{l}\text { Verbal } \\
\text { structure } \\
\text { task }\end{array}$} & Imagine you are a visual stimulus on your way through the eye. \\
\hline & \begin{tabular}{|l|l}
1 & $\begin{array}{l}\text { Please, name all "places" and "streets" you are passing on your way. (Places = } \\
\text { structures or similar elements, streets = neuronal paths or similar entities). }\end{array}$ \\
\end{tabular} \\
\hline & 2 Leave out all "places" and "streets" you don't pass by. \\
\hline & $\begin{array}{l}3 \begin{array}{l}\text { If you don't know the exact name of a place or street, simply write down, how } \\
\text { we can identify the "place" or "street" (for example, its function, what happens } \\
\text { there, a short description). }\end{array} \\
\end{array}$ \\
\hline & $\begin{array}{l}\text { Now start listing up the elements according to the sequence of contact with the } \\
\text { visual stimulus. Start with the first part of the eye. }\end{array}$ \\
\hline \multirow[t]{2}{*}{$\begin{array}{l}\text { Drawing } \\
\text { task }\end{array}$} & $\begin{array}{l}1 \text { Here, you see the cross section of the eye from above. The front of the eye ball is } \\
\text { fragmented. Please, draw in the missing structures of the front as exactly and } \\
\text { detailed as you can! }\end{array}$ \\
\hline & \begin{tabular}{|l|l}
2 & $\begin{array}{l}\text { Finally, mark the places where a) the area of most distinct vision and } b \text { ) the } \\
\text { optic disk are positioned and label them! }\end{array}$
\end{tabular} \\
\hline $\begin{array}{l}\text { Labelling } \\
\text { task }\end{array}$ & $\begin{array}{l}\text { Here, once again you see the cross section of the eye. Please label the numbered } \\
\text { elements. }\end{array}$ \\
\hline $\begin{array}{l}\text { Transfer } \\
\text { task }\end{array}$ & $\begin{array}{l}\text { Imagine that a friend of yours no longer sees very well with one eye. What possible } \\
\text { reasons are there for this? Please list all your ideas about what parts of the eye are } \\
\text { malfunctioning! }\end{array}$ \\
\hline
\end{tabular}

In order to measure active cognitive processing, we introduced a scale of six items that was intended to measure elaborative learning strategies. The items were drawn from Schiefele (1990, 1991), who selected these items in accordance with the questionnaires of Pintrich, Smith, Garcia and McKeachie (1993) as well as Weinstein (1987) and the classification of learning strategies of Schnotz (1986). The items were rated on a fivepoint Likert scale (not correct at all, hardly correct, slightly correct, fairly correct, and absolutely correct).

The performance test consisted of a structure task, a drawing task, a labelling task, and a transfer task.

- The structure task required the students to name those structures of the eye passed by a visual stimulus on its way through the eye, and to arrange them according to the sequence of contact (cornea, pupil, lens, vitreous body, retina, optic disk, and optic nerve). For each element listed in the correct order a maximum of one point 
was scored. The elements that were mentioned without being in the list of correct answers (like ciliary muscle or sclera) were also counted (superfluous details).

- Then, the incomplete schematic picture of a horizontal section through the eye used in the instructions had to be completed by drawing. Relevant parts were eliminated and had to be redrawn (cornea, iris, lens, ciliary muscles) or their place had to be marked (optic disc and fovea). The drawing scale was made up of 6 items.

- Following this, the participants had to name nine parts of the eye (cornea, iris, lens, ciliary muscles, vitreous body, sclera, choroid, retina, and optic nerve). The same picture as in the programs was used; relevant parts were marked. These nine items formed the scale labelling.

- The transfer task demanded that learners use their knowledge in order to find explanations for a given situation (see Table 3). Based on the presented information, 16 reasons were accepted. They were coded into nine items, as multiple causes that referred to one part of the eye (e.g. lens is clouded or inflexible) were put together.

Table 4 lists the number of items, means, standard deviations, reliabilities (Cronbach's alpha, a measure of internal consistency) and objectivities of the measurement scales used. Performance scales were normed to the range of 0 to 100, thus enabling scores to be interpreted as percent correct answers; for superfluous details, only their frequency was counted. Elaboration ratings were normed to their rating range of 1 to 5 . Cronbach's alphas of all performance scales were low, but as all tests are assessed as criteria tests, this is not relevant. Content validity of all performance tests is given; the questions of the performance tests were constructed from the presented content of the instructions. Two raters scored all of the performance tests. The Pearson correlation of sum scores was used as a measure of scale objectivity.

Table 4: Features of the measurement scales

(alpha $=$ Cronbach's alpha; $\mathrm{r}_{\text {interrater }}=$ objectivity; $\mathrm{n}=65$ )

\begin{tabular}{|l|l|c|c|c|c|c|}
\hline \multicolumn{2}{|c|}{} & Items & $\mathrm{M}$ & $\mathrm{SD}$ & alpha & $\mathrm{r}_{\text {interrater }}$ \\
\hline Control scale & Prior knowledge & 8 & 40.96 & 15.86 & .28 & -- \\
\hline Active processing & Elaborative learning strategies & 6 & 2.84 & .63 & .54 & -- \\
\hline Performance & Verbal structure: correct details & 7 & 79.12 & 17.87 & .44 & .90 \\
\cline { 2 - 7 } & Verbal structure: superfluous details & -- & .97 & 1.08 & -- & .90 \\
\cline { 2 - 7 } & Labelling picture & 9 & 88.97 & 13.38 & .51 & .96 \\
\cline { 2 - 7 } & Drawing & 6 & 63.85 & 18.30 & .38 & .88 \\
\cline { 2 - 7 } & Transfer & 9 & 44.79 & 19.04 & .40 & .88 \\
\hline
\end{tabular}

Finally, the program usage was registered by the computer. The total learning times of the introduction, the summary, glossary units and detailed texts were computed and related to 13 minutes' study time. Thus percentaged learning times are reported. Detailed texts are the texts that were addressed via pictures. Furthermore, the number of texts that had been worked through was counted for each text category.

\section{Statistical methods}

The effects of text style, i.e. personalised and formal texts, and prior knowledge on amount of worked through text categories (introduction, detailed texts, summary, and glossary units) were analysed via non-parametric methods. No interaction effects of prior knowledge with text style were analysed because data were not adequately distributed in order to calculate them; most cells in completely arranged cross tables 
counted less than 5. For testing group differences concerning the use of the introduction, the summary and the detailed texts, $2 \times 2$ cross tables were analysed by Fisher's exact test (personalised vs. formal text $x$ introduction read vs. unread, summary read vs. unread, and 13 detailed texts read vs. 12 or less read). For Fischer's exact test, $w$ was computed as effect size, which is normally used with chi-square tests (Cohen, 1988). The frequency of glossary units was analysed by U-test instead of a ttest, because distribution of data was not normal. The pointbiserial correlation $r_{p b}$ was computed as effect size. $w$ and $\mathrm{r}_{\mathrm{pb}}$ of range .10 to .30 are interpreted as small, of range .30 to .50 as medium, and of $>.50$ as large (Cohen, 1988). The effects of prior knowledge on program usage were analysed by computing pointbiserial correlations $\mathrm{r}_{\mathrm{pb}}$, which are also used as effect size.

The various dependent measures of study time, elaborative processing and performance were subjected to a series of one-way analysis of covariance (ANCOVA), with the between subjects factor being text style and prior knowledge serving as covariate. In the statistical models, the interaction between text style and prior knowledge was included. Furthermore, a sequential square-sum decomposition (SPSS Type I) was administered along the sequence prior knowledge, text style and interaction. Reported means and standard deviations of the treatment groups were corrected by the statistical influence of prior knowledge. Directions of effects of the continuous covariable prior knowledge were represented by correlations. Significant interaction effects were analysed post-hoc by splitting treatment groups by the median of prior knowledge in order to provide a comparison between treatment groups concerning low or high prior knowledge learners. The median of prior knowledge was $50.00 \%$ correct answers. Subjects with values equal to the median were assigned to the group with values more than the median. Assumptions of normality and homogeneity of variance could mostly be retained. As an ANCOVA is regarded to be very robust to most plausible violations of the usual assumptions (Bortz, 2005; Olejnik \& Algina, 1984; Wu, 1984), the strategy of statistical analyses was not changed. Partial etasquared effect sizes were computed. Partial eta-squared of range .01 to 06 are interpreted as small, of range .06 to .14 as medium and of > .14 as large (Cohen, 1988).

\section{Results}

Older research showed a methodological problem due to incomplete work-through of learner-controlled instructions, compared to system-controlled instructions (Lepper, 1985; Williams, 1996). Therefore, the program usage of the learners was analysed in order to assure that this aspect is not confounded with experimental conditions and hence that the subsequent analyses on elaboration processes and performance can be referred to prior knowledge and text style.

Both experimental groups tended to work through the whole program within the 13 minutes' study time (see Table 5). 49 students studied all text units, 5 left out one unit, 9 left out two units, and 1 student each left out three and four units. First it was controlled, if the groups were similar concerning the amount of information units studied. No differences in program usage were found in respect of introduction (ns, $w$ $=.08)$, summary (ns, $w=.12)$, and detailed texts $(\mathrm{ns}, w=.04)$ as well as with respect to glossary units (formal style: mean rank $=30.98$, personalised style: mean rank $=35.08$, $\mathrm{U}=461.50, \mathrm{~ns}, \mathrm{r}_{\mathrm{pb}}=.11$ ). Prior knowledge did not play a role for using the introduction $\left(\mathrm{r}_{\mathrm{pb}}=.08, \mathrm{~ns}\right)$, the summary $\left(\mathrm{r}_{\mathrm{pb}}=.00, \mathrm{~ns}\right)$, the detailed texts $\left(\mathrm{r}_{\mathrm{pb}}=.10, \mathrm{~ns}\right)$, and the glossary $(r=-.04, n s)$. Furthermore, no effects on the usage of programs were found as 
measured by percentage study time (see Table 6). Generally, text style did not influence the way learners realised their study behavior and the level of the learners' prior knowledge also did not matter in respect of program usage. Hence potential effects on learning outcomes should not be attributed to program usage styles as represented by the dependent measures chosen.

Table 5: How many text units were worked through by the groups?

\begin{tabular}{|c|c|c|c|c|c|c|}
\hline \multirow{2}{*}{$\begin{array}{l}\text { Number of } \\
\text { detailed texts } \\
\text { studied }\end{array}$} & \multirow{2}{*}{$\begin{array}{c}\text { The } \\
\text { summary } \\
\text { was studied }\end{array}$} & \multicolumn{2}{|c|}{$\begin{array}{c}\text { The introduction } \\
\text { was studied }\end{array}$} & \multirow{2}{*}{$\begin{array}{c}\begin{array}{c}\text { Personalised } \\
\text { text group }\end{array} \\
\text { Sum }\end{array}$} & \multirow{2}{*}{$\begin{array}{c}\begin{array}{c}\text { Formal } \\
\text { text group }\end{array} \\
\text { Sum }\end{array}$} & \multirow{2}{*}{$\begin{array}{c}\text { All } \\
\text { Sum }\end{array}$} \\
\hline & & No & Yes & & & \\
\hline \multirow[t]{2}{*}{11} & No & $0 / 1$ & $0 / 0$ & 0 & 1 & 1 \\
\hline & Yes & $0 / 0$ & $0 / 1$ & 0 & 1 & 1 \\
\hline \multirow[t]{2}{*}{12} & No & $0 / 1$ & $1 / 1$ & 1 & 2 & 3 \\
\hline & Yes & $0 / 0$ & $2 / 0$ & 2 & 0 & 2 \\
\hline \multirow[t]{2}{*}{13} & No & $3 / 3$ & $0 / 1$ & 3 & 4 & 7 \\
\hline & Yes & $1 / 1$ & $25 / 24$ & 26 & 25 & 51 \\
\hline & & & & & & 65 \\
\hline
\end{tabular}

Notes for Table 5

The content was covered by 1 introduction, 13 detailed texts, and 1 summary. The numbers before the slash represent the numbers of pupils in the personalised-text group; the numbers after the slash represent the numbers of pupils in the formal-text group. For example, the number 24 in the yellow backgrounded cell in the table indicates that 24 pupils of the formal-text group had studied all of the detailed texts as well as the introduction and the summary; the first number 1 in the seagreen backgrounded cell in the table indicates that one pupil in the personalised-text group had studied 12 of the 13 detailed texts and the introduction, but had not studied the summary.

Results for elaboration ratings revealed a significant interaction effect between prior knowledge and text style (see Table 6), but no main effects. Low knowledge students using personalised texts engaged in higher processing load as when studying formal texts $\left(\mathrm{M}_{\text {formal }}=2.58, \mathrm{SD}=.66, \mathrm{n}=14, \mathrm{M}_{\text {personalised }}=2.93, \mathrm{SD}=.61, \mathrm{n}=18, \mathrm{t}(30)=1.52, \mathrm{p}<\right.$ .07 , one-sided), whereas higher knowledge learners showed a reversed pattern $\left(\mathrm{M}_{\mathrm{formal}}\right.$ $=3.11, \mathrm{SD}=.65, \mathrm{M}_{\text {personalised }}=2.61, \mathrm{SD}=.49$, Welch-t(30.99) $=-2.52, \mathrm{p}<.01$, one-sided). Personalisation had a positive effect on low prior knowledge learners, but a negative effect on higher prior knowledge learners.

Results for performance showed a marginally significant main effect of prior knowledge, significant main effects of text style, and a significant prior-knowledge by text-style interaction effect (see Table 6). For structural knowledge as measured by listing correct elements, a significant main effect and a marginally significant interaction effect $(p \leq .055)$ were found. As the interaction effect only slightly missed the significance level, it is included in the interpretation of results. Thereby, low priorknowledge learners using personalised messages scored higher on this task $\left(\mathrm{M}_{\text {formal }}=\right.$ 66.33, $\mathrm{SD}=26.64, \mathrm{M}_{\text {personalised }}=84.13, \mathrm{SD}=12.86$, Welch-t $(17.69)=2.30, \mathrm{p} \leq .015$, onesided), whereas higher prior knowledge learners did score equally well with formal and personalised texts $\left(\mathrm{M}_{\text {formal }}=81.20, \mathrm{SD}=14.33, \mathrm{M}_{\text {personalised }}=82.65, \mathrm{SD}=11.45, \mathrm{t}(31)=\right.$ $.31, \mathrm{~ns})$. This effect is similar to the effect on elaboration ratings. This interaction effect is accompanied by a marginal main effect of prior knowledge $(p \leq .10)$ on listing superfluous details. With formal as well as personalised texts, students tended to list less irrelevant elements in the structural task with higher prior knowledge $(r=-.30)$. 
Table 6: ANCOVAs of program usage, elaboration and performance $\left({ }^{*} \mathrm{p} \leq .05,{ }^{* *} \mathrm{p} \leq .01\right)$

\begin{tabular}{|l|l|c|c|c|c|c|c|}
\hline \multirow{2}{*}{} & \multicolumn{2}{c|}{$\begin{array}{c}\text { Prior } \\
\text { knowledge }\end{array}$} & \multicolumn{2}{c|}{$\begin{array}{c}\text { Text } \\
\text { style }\end{array}$} & \multicolumn{2}{c|}{$\begin{array}{c}\text { Prior knowledge } \\
\text { x text style }\end{array}$} \\
\cline { 3 - 8 } & $\mathrm{F}(1,106)$ & Partial eta $^{2}$ & $\mathrm{~F}(1,106)$ & Partial eta $^{2}$ & $\mathrm{~F}(1,106)$ & Partial eta $^{2}$ \\
\hline \multirow{3}{*}{$\begin{array}{l}\text { Program } \\
\text { usage }\end{array}$} & Introduction & .10 & .00 & .31 & .01 & .53 & .01 \\
\cline { 2 - 8 } & Detailed texts & .18 & .00 & .04 & .00 & 1.35 & .02 \\
\cline { 2 - 8 } & Summary & .00 & .00 & .00 & .00 & 1.39 & .02 \\
\cline { 2 - 8 } & Glossary units & .21 & .00 & .01 & .00 & .16 & .00 \\
\hline Elaboration & 1.86 & .03 & .24 & .00 & $6.01^{*}$ & .09 \\
\hline \multirow{5}{*}{$\begin{array}{l}\text { Performance } \\
\end{array}$} & $\begin{array}{l}\text { Verbal structure: } \\
\text { correct details }\end{array}$ & 2.62 & .04 & $5.16^{*}$ & .08 & 3.83 & .06 \\
\cline { 2 - 8 } & $\begin{array}{l}\text { Verbal structure: } \\
\text { superfluous details }\end{array}$ & 3.26 & .05 & .86 & .01 & .46 & .01 \\
\cline { 2 - 8 } & Labelling pictures & 2.67 & .04 & $10.14^{* *}$ & .14 & 1.77 & .03 \\
\cline { 2 - 8 } & Drawing & .86 & .01 & $4.83^{*}$ & .07 & 1.01 & .02 \\
\cline { 2 - 8 } & Transfer & .32 & .01 & .14 & .00 & $7.24 * *$ & .11 \\
\hline
\end{tabular}

For performance concerning labelling pictures and completing pictures by drawing, pure main effects of personalisation were found, revealing medium to high effect sizes and strongly confirming personalisation effects (see Table 6). With personalised texts, pupils could recall more names of pictorial structures as well as draw missing elements well shaped and in the correct place into an incomplete picture than with formal texts (see Table 7).

Table 7: Mean scores and standard deviations of program usage, elaboration and performance.

\begin{tabular}{|l|l|c|c|c|c|}
\hline \multicolumn{2}{|c|}{} & \multicolumn{2}{|c|}{$\begin{array}{c}\text { Formal } \\
\text { text style }\end{array}$} & \multicolumn{2}{c|}{$\begin{array}{c}\text { Personalised } \\
\text { text style }\end{array}$} \\
\cline { 3 - 6 } \multicolumn{2}{c|}{} & $\mathrm{M}$ & $\mathrm{SD}$ & $\mathrm{M}$ & $\mathrm{SD}$ \\
\hline \multirow{3}{*}{$\begin{array}{l}\text { Program } \\
\text { usage }\end{array}$} & Introduction & 5.67 & 4.71 & 6.42 & 5.35 \\
\cline { 2 - 6 } & Detailed texts & 75.18 & 14.02 & 74.37 & 10.77 \\
\cline { 2 - 6 } & Summary & 13.94 & 12.36 & 14.05 & 10.56 \\
\cline { 2 - 6 } & Glossary units & 5.22 & 7.41 & 5.15 & 5.63 \\
\hline Elaboration & 2.88 & .69 & 2.79 & .57 \\
\hline \multirow{2}{*}{$\begin{array}{l}\text { Perform- } \\
\text { ance }\end{array}$} & Verbal structure: correct details & 74.89 & 21.44 & 83.48 & 12.09 \\
\cline { 2 - 6 } & Verbal structure: superfluous details & 1.06 & 1.09 & .88 & 1.07 \\
\cline { 2 - 6 } & Labelling pictures & 84.51 & 16.06 & 93.58 & 7.74 \\
\cline { 2 - 6 } & Drawing & 59.34 & 18.37 & 68.49 & 17.29 \\
\cline { 2 - 6 } & Transfer & 45.45 & 18.50 & 44.10 & 19.85 \\
\hline
\end{tabular}

Notes for Table 7

Performance scales were normed to the range of 0 to 100 , thus enabling scores to be interpreted as percent correct answers; for superfluous details, only their frequency was counted. Elaboration ratings were normed to their rating range of 1 to 5 . The total learning times of the introduction, the summary, the glossary units and the detailed texts were computed and related to 13 minutes' study time, so that scores can be read as "percent learning time".

For transfer performance, a significant interaction effect was found. Thereby, a personalisation effect occurred with low prior knowledge learners $\left(\mathrm{M}_{\text {formal }}=39.68\right.$, SD $=21.22, \mathrm{M}_{\text {personalised }}=50.00, \mathrm{SD}=17.98, \mathrm{t}(30)=1.49, \mathrm{p} \leq .07$, one-sided). Learners using personalised texts could better solve the transfer problem than learners using formal texts. With higher prior knowledge, the effect seems to invert $\left(\mathrm{M}_{\text {formal }}=49.71, \mathrm{SD}=\right.$ 
$15.44, \mathrm{M}_{\text {personalised }}=36.51, \mathrm{SD}=20.17, \mathrm{t}(31)=-2.13, \mathrm{p} \leq .02$, one-sided $)$. The group with formal texts had more success than the personalised text group. This effect strongly corresponds to the results for elaboration processes.

\section{Discussion}

Personalisation had the expected positive effects on learning for low prior knowledge learners (Moreno \& Mayer, 2000, 2004; Mayer et al., 2004), but produced mixed results for higher prior knowledge learners. A clear pattern of results has appeared with low prior knowledge learners. Personalised texts increased success in labelling and drawing pictures as well as structural knowledge and transfer performance. This corresponds to higher ratings of elaboration processes by low prior knowledge learners in comparison to high knowledge learners. Allowing high prior knowledge learners to study personalised texts also increased success in labelling and drawing pictures, but had no and negative effects on structural knowledge and transfer performance, respectively. Especially the transfer effect corresponds to the effect on ratings of elaboration. Thereby, learners showed lower ratings of elaboration with personalised texts in comparison to formal texts.

How could this pattern of results be explained? In theoretical aspects, the pattern of results might not be easily and solely explained in respect of social agency theory. Especially, if a positive effect of personalisation on learning is assumed in general, it should not depend on prior knowledge. Every learner should engage in deeper learning due to social cues triggering a social response and thus increasing effort on processing information, resulting in better test performance on various tasks. If it is assumed that social cues are simply not as important for high as for low knowledge learners, this might lead to smaller effects of personalisation with more expertise. The kind of task might be influencing the effects, but a satisfying answer why there are divergent effects on tasks cannot be thought of. This must be especially noticed, because the high prior knowledge learners in this study are no experts, they only show more prior knowledge on simple multiple choice recognition tasks, whereby no pupil solved all questions correctly. Definitely, only five questions were solved in maximum. So, the variance of prior knowledge is relatively small.

In addition to a social agency theory perspective, an explanation could be given with the help of expertise reversal effects in multimedia learning (Kalyuga, 2007), which is focussed on cognition. A hint is given by the pattern of results shown by the high knowledge learners. This shows a separation of effects between picture oriented and text oriented performance tasks. While sheer pictorial knowledge as measured by the drawing task and integrated verbal-pictorial knowledge, as measured by the labelling task benefit from personalisation, verbal tasks suffer from personalisation. This indicates that it might be prior knowledge, which has to be considered for explanation. The verbal oriented prior knowledge test in this study is considered to test verbal factual knowledge (elements' names and functions) and it might be assumed that all pupils would have scored low in a pictorial prior knowledge test, because their knowledge level was low in general. We might further assume that this proposed pattern of prior knowledge has led to the pattern of results, i.e. pure personalisation effects with all learners in respect of pictorial tasks due to all learners being low on pictorial knowledge, and vanishing or even reversal effects (expertise reversal effects) with higher knowledge learners in respect of verbal performance tasks due to having 
some variance in basic knowledge. Kalyuga (2007) also mentioned that expertise could be more narrowly viewed as task-specific expertise, thus it might well be that one is good in verbally solving performance tasks while being poor at picture oriented tasks.

This kind of explanation by task-specific effects could better be referred to a view of personalisation in aspects of self-referenced information processing. Thus, for low prior knowledge learners, personalisation offers a schema - one's own eyes - in order to construct knowledge around and in that schema, whereby forcing higher knowledge pupils to process information in reference to one's own eye might disturb them to construct knowledge around and in a general schema of an eye (some information might be redundant). This could explain effects in this study.

In methodical aspects, we have found equivalence between measures of transfer performance and elaboration ratings. Elaboration ratings should especially measure the amount of integration processes, which is responsible for a good transfer performance according to Mayer (2005b). On the other hand, elaboration ratings were not indicative for the integration of verbal and pictorial knowledge as measured by labelling pictures. A closer view on the items reveals that they target on elaboration processes going beyond simply referring the verbal and pictorial information of the instruction. Thus, this kind of elaboration measurement could eventually be a closer measure of processing than performance.

Further on, the diversity of performance measures does bring out this changing pattern of results. If we had administered only the commonly used retention and transfer tests, we would have made apparent only unwanted effects of personalisation, especially for transferable knowledge. Nevertheless, there are still more arguments in favour of personalised texts. Considering that the kind of instructions used in this study aim for structural knowledge of the eye, i.e. about the elements of the eye, their functions and their spatial relation to each other, it is still preferable to use personalised texts regardless of prior knowledge, because learning is promoted. Only in aspects of transfer performance was personalisation found to be harmful, but normally instructions fostering learning in aspects of transfer would show how a human eye functions. In other words, the instructions used in this study could be seen as a pretraining after which students can better construct a causal model of the eye, i.e. how the eye functions as a whole (pretraining principle, Mayer, 2005a).

\section{Conclusions}

In future, four aspects should be focussed on:

1. In theoretical aspects, especially the social agency theory should be investigated more precisely in order to show whether this should be the preferred way to explain personalisation effects. Concurrently, a cognitively based explanation might be more preferable and able to explain interaction effects. Alternatively, it is quite reasonable to assume that both cognitive and motivational aspects are working together to bring forth personalisation effects.

2. In methodical aspects, use a variety of performance measures is recommended, in order to show the multi-level diversity of effects. It must be assumed that personalisation has no straightforward effect on any reasonable performance measure. 
3. In empirical aspects, personalisation effects are assumed to depend on prior knowledge like other prominent effects also do. Therefore, we must gain more knowledge about learner characteristics that determine whether personalisation is successful or not. This knowledge can be used in order to adapt instructions to learners.

4. In practical aspects, it is still further recommended to personalise messages, because regardless of prior knowledge students learned better with personalised messages in view of the didactical aim of the instruction used in this study. For example, when the aim is to construct an adequate knowledge structure before a structure's functioning is investigated, it is less important to foster transfer performance.

\section{References}

Bortz, J. (2005). Statistik für Human- und Sozialwissenschaftler [Statistics for human and social sciences]. Heidelberg: Springer.

Cohen, J. (1988). Statistical power analysis for the behavioral sciences. New York: Erlbaum.

Cortina, J. M. \& Nouri, H. (2000). Effect sizes for ANOVA designs. Thousand Oaks, CA: Sage.

Hidi, S. \& Baird, W. (1988). Strategies for increasing text-based interest and students' recall of expository texts. Reading Research Quarterly, 23, 465-483.

Kalyuga, S. (2007). Expertise reversal effect and its implications for learner-tailored instruction. Educational Psychology Review, 19, 509-539.

Keller, J. M. \& Suzuki, K. (1988). Use of the ARCS motivation model in courseware design. In D. H. Jonassen (Ed), Instructional designs for microcomputer courseware (pp. 289-320). Hillsdale, NJ: Erlbaum.

Lepper, M. R. (1985). Microcomputers in education: Motivational and social issues. American Psychologist, 40, 1-18.

Mayer, R. E. (2001). Multimedia learning. New York: Cambridge University Press.

Mayer, R. E. (2005a). Principles for managing essential processing in multimedia learning: segmenting, pretraining, and modality principles. In R. E. Mayer (Ed), The Cambridge handbook of multimedia learning (pp. 169-182). New York: Cambridge University Press.

Mayer, R. E. (2005b). Principles of multimedia learning based on social cues: Personalization, voice, and image principles. In R. E. Mayer (Ed), The Cambridge handbook of multimedia learning (pp. 201-212). New York, NY: Cambridge University Press.

Mayer, R. E. Fennell, S., Farmer, L. \& Campbell, J. (2004). A personalization effect in multimedia learning: Students learn better when words are in conversational style rather than formal style. Journal of Educational Psychology, 96, 389-395.

Moreno, R. \& Mayer, R. E. (2000). Engaging students in active learning: The case for personalized multimedia messages. Journal of Educational Psychology, 92, 724-733.

Moreno, R. \& Mayer, R. E. (2004). Personalized messages that promote science learning in virtual environments. Journal of Educational Psychology, 96, 165-173. 
Olejnik, S. F. \& Algina, J. (1984). Parametric ANCOVA and the Rank Transform ANCOVA when the data are conditionally non-normal and heteroscedastic. Journal of Educational Statistics, 9, 129-149.

Pintrich, P. R., Smith, D. A. F., Garcia, T. \& McKeachie, W. J. (1993). Predictive validity and reliability of the Motivated Strategies for Learning Questionnaire. Educational and Psychological Measurement, 53, 801-813.

Reeves, B. \& Nass, C. (1996). The media equation. New York: Cambridge University Press.

Renninger, K. A., Hidi, S. \& Krapp, A (1992). The role of interest in learning and development. Hillsdale, NJ: Erlbaum.

Rogers, T. B., Kuiper, N. A. \& Kirker, W. S. (1977). Self reference and the encoding of personal information. Journal of Personality and Social Psychology, 35, 677-688.

Schiefele, U. (1990). Thematisches Interesse, Variablen des Leseprozesses und Textverstehen [Topic interest, reading process variables, and text comprehension]. Zeitschrift für Experimentelle und Angewandte Psychologie, 37, 304-332.

Schiefele, U. (1991). Interesse und Textrepräsentation - Zur Auswirkung des thematischen Interesses auf unterschiedliche Komponenten der Textrepräsentation unter Berücksichtigung kognitiver und motivationaler Kontrollvariablen [Interest and text representation: The influence of topic interest on different components of text representation]. Zeitschrift für Pädagogische Psychologie, 5, 245-259.

Sweller, J. (1999). Instructional design in technical areas. Camberwell, Victoria: ACER Press.

Symons, C. S. \& Johnson, B. T. (1997). The self-reference effect in memory: A meta-analysis. Psychological Bulletin, 121, 371-394.

Turco, R. M. (1996). Self-referencing, quality of argument, and persuasion. Current Psychology: Developmental, Learning, Personality, Social, 15, 258-276.

Wade, S. E. (1992). How interest affects learning from text. In K. A. Renninger, S. Hidi \& A. Krapp (Eds), The role of interest in learning and development (pp. 255-277). Hillsdale, NJ: Erlbaum.

Weinstein, C. E. (1987). Learning and Study Strategies Inventory (LASSI). Clearwater, FL: H \& H Publishing Company.

Williams, M. D. (1996). Learner-control and instructional techniques. In D. H. Jonassen (Ed), Handbook of research for educational communications and technology (pp. 957-983). New York: Macmillan.

Wu, Y. B. (1984). The effects of heterogenous regression slopes on the robustness of two test statistics in the analysis of covariance. Educational and Psychological Measurement, 44, 647-663.

Klaus D. Stiller and Rosemarie Jedlicka

Institute for Psychology, University of Regensburg

Universitätsstrasse 31, 93053 Regensburg, Germany

Correspondence: klaus.stiller@psychologie.uni-regensburg.de 